\title{
Looking beyond symptoms and disease activity to define disease severity in inflammatory bowel disease: results of an IOIBD specialist panel
}

Corey A. Siegel ${ }^{1}$, Cynthia B. Whitman², Brennan M.R. Spiegel ${ }^{2}$, Brian Feagan ${ }^{3}$, Bruce Sands ${ }^{4}$, Edward V Loftus Jr ${ }^{5}$, Remo Panaccione ${ }^{6}$, Geert D'Haens ${ }^{7}$, Charles N. Bernstein $^{8}$, Richard Gearry ${ }^{9}$, Siew Ng ${ }^{10}$, Gerassimos J. Mantzaris ${ }^{11}$, Balfour Sartor ${ }^{12}$, Mark S. Silverberg ${ }^{13}$, Robert Riddell ${ }^{13}$, Ioannis Koutroubakis ${ }^{14}$, Colm O'Morain ${ }^{15}$, Peter L. Lakatos $^{16}$, Dermot P.B. McGovern ${ }^{2}$, Jonas Halfvarson ${ }^{17}$, Walter Reinisch ${ }^{18}$, Gerhard Rogler $^{19}$, Wolfgang Kruis ${ }^{20}$, Curt Tysk ${ }^{17}$, Stefan Schreiber ${ }^{21}$, Silvio Danese ${ }^{22}$, William Sandborn $^{23}$, Anne Griffiths ${ }^{24}$, Bjorn Moum ${ }^{25}$, Christoph Gasche ${ }^{26}$, Francesco Pallone ${ }^{27}$, Simon Travis ${ }^{28}$, Julian Panes ${ }^{29}$, Jean Frederic Colombel ${ }^{4}$, Stephen Hanauer ${ }^{30}$, Laurent Peyrin-Biroulet ${ }^{31}$

1. Dartmouth-Hitchcock Inflammatory Bowel Disease Center, Dartmouth-Hitchcock Medical Center, Lebanon, $\mathrm{NH}$,

United States.

2. Cedars-Sinai Medical Center, Department of Health Services, Los Angeles, CA, United States.

3. Robarts Clinical Trials, London, ON, Canada.

4. Icahn School of Medicine at Mount Sinai, New York, NY, United States.

5. Mayo Clinic, Rochester, MN, United States.

6. University of Calgary, Calgary, AB, Canada.

7. Academic Medical Center, Amsterdam, Netherlands.

8. University of Manitoba, Winnipeg, MB, Canada.

9. University of Otago, Christchurch, New Zealand.

10. Chinese University of Hong Kong, Hong Kong, Hong Kong.

11. Evangelismos-PolyCliniki-Ophthalmiatreion Hospital, Athens, Greece.

12. University of North Carolina, Chapel Hill, NC, United States.

13. Mount Sinai Hospital, Toronto, ON, Canada.

14. University Hospital Heraklion, Crete, Greece.

15. Charlemont Clinic, Dublin, Ireland.

16. Semmelweis University, Budapest, Hungary.

17. Örebro University, Orebro, Sweden.

18. McMaster University, Hamilton, ON, Canada.

19. University Hospital of Zürich, Zurich, Switzerland.

20. University of Cologne, Koln, Germany.

21. University Hopital Schleswig Holstein, Kiel, Germany.

22. Humanitas University, Milan, Italy.

23. UCSD, San Diego, CA, United States.

24. Hospital for Sick Children, Toronto, ON, Canada.

25. Oslo University, Oslo, Norway.

26. Medical University and General Hospital Vienna, Vienna, Austria.

27. University of Rome, Rome, Italy.

28. Oxford University Hospital, Oxford, United Kingdom.

29. Hospital Clinic de Barcelona, IDIBAPS, CIBERehd, Barcelona, Spain.

30. Northwestern Feinberg School of Medicine, Chicago, IL, United States.

31. Inserm U954 and CHU de Nancy, Lorraine Univeristy, Nancy, France.

\author{
Correspondence to: \\ Dr. Corey A. Siegel \\ Inflammatory Bowel Disease Center \\ Section of Gastroenterology and Hepatology \\ Dartmouth-Hitchcock Medical Center \\ Lebanon, $\mathrm{NH} 03756$ \\ p (603) 6508101 \\ f (603) 6504481 \\ email: corey.a.siegel@hitchcock.org
}




\begin{abstract}
Background and Aim: The aims of this study were to select the attributes determining disease severity, to rank the importance of and to score these individual attributes for both Crohn's disease (CD) and ulcerative colitis (UC).

Methods: Using a modified Delphi panel, 14 members of the International Organization for the Study of Inflammatory Bowel Diseases (IOIBD) selected the most important attributes.18 IOIBD members independently completed a conjoint analysis exercise. Following group discussion, these specialists then repeated the conjoint analysis exercise, first as a group and then independently to yield a final relative ranking of these attributes. Adjusted utilities were developed by creating proportions for each level within an attribute.

Results: For CD $15.8 \%$ of disease severity was attributed to the presence of mucosal lesions, $10.9 \%$ to history of a fistula, $9.7 \%$ to history of abscess and $7.4 \%$ to history of intestinal resection. For UC $18.1 \%$ of disease severity was attributed to mucosal lesions, followed by $14.0 \%$ for impact on daily activities, $11.2 \%$ C-reactive protein and $10.1 \%$ for prior experience with biologics. Disease severity scores were created on a 100-point scale by applying each attribute's average importance to the adjusted utilities.
\end{abstract}

Conclusion: Based on specialist opinion, mucosal lesions were the most important attribute associated with disease severity for both diseases. CD severity was associated more with intestinal damage, in contrast to UC disease severity, which was more dependent on symptoms and impact on daily life. Disease severity indices may provide a useful tool for consistent assessment of patients with IBD. 


\section{Introduction}

Inflammatory bowel disease (IBD) includes Crohn's disease (CD) and ulcerative colitis (UC), which are chronic disabling conditions.[1-3] There is accumulating evidence indicating that we need to treat beyond symptoms due to the well-known disconnect between clinical symptoms and disease activity, especially in CD. IBD are destructive diseases which may result in irreversible bowel damage and the need for surgery. Avoidance of hospitalization surgery and progression to bowel damage are increasingly considered as a therapeutic goals in disease-modification trials.[4-9] The premise is to treat inflammatory disease before intestinal damage becomes irreversible and disability ensues.

Disease activity and disease severity may refer to two distinct yet overlapping concepts. Disease activity reflects a cross sectional assessment of biological severity whereas disease severity may include longitudinal and historical factors which gives a more complete picture of the overall burden of disease. To be included in the registration clinical trials for biologics, IBD patients had to have moderate to severely active disease (often abbreviated to the simplistic 'severe disease') according to the Crohn's Disease Activity Index (CDAI) for CD or Mayo Score for UC, both of which were developed to measure disease activity at a point in time.[10-12] However, basing disease severity on symptoms alone misses the many other patient and disease characteristics that drive our decisions towards appropriate medical therapy, including bowel damage and impact on daily activities (disability). Since the labels for biologic drugs are based on the registration trials, these disease-modifying medications are limited to patients with moderate to severe disease activity. Therefore, patients need to have substantial enough symptoms at the time of prescribing for doctors to recommend and payers to 
agree to initiate treatment, even if the past pattern or burden of disease would be likely to benefit from treatment in those with disease that is currently less active or inactive.

A patient's historical disease course and risk of future complications are important features of IBD that should also guide management. In an effort to shift the paradigm from stratifying patients based on current disease activity towards global course of disease severity, researchers conducted a systematic review identifying three main domains relevant to the evaluation of disease severity in IBD: inflammatory burden, disease course and impact of the disease on the patient's daily activities,..[10] There are multiple attributes within these domains, some of which have more influence over long term disease course than others.

The aims of this study were to: 1 . Define the attributes within these three domains that are most important to determining disease severity; 2. Rank the importance of and score these individual attributes for both $C D$ and $U C$; and 3. With these rankings and an understanding of how much each attribute contributes to overall disease severity, to generate a disease severity index to place an individual's disease in context.

\section{Methods:}

\section{PHASE 1: Identification of Key Attributes}

Determining the main patient attributes influencing determination of IBD severity began with a systematic review process to identify all potential elements of disease activity and severity of IBD. Using a set of predefined MeSH terms, researchers conducted a comprehensive literature search in PubMed from inception until April 2014. During the systematic review, researchers identified three domains instrumental in determining IBD severity: impact on the patient, inflammatory burden, and course of complication.[10] 
After a list of attributes was identified, 16 IBD experts met in Frankfurt, Germany on December $10-11^{\text {th }}, 2014$ to discuss the results using a modified RAND panel. With the intention of reviewing and short-listing the list of attributes identified through the systematic review, an open discussion ensued. There was an automated response process and participants voted on the attributes on the list by assigning values 1-9 (with 9 being the most preferred) to each of the attributes on the list. Variables that received a score ranging from $7-9$ by at least $75 \%$ of participants were included in the final attribute set. For those attributes not initially receiving a score between 7-9, following a group discussion, a secondary vote was initiated. At this point, if an attribute received fewer than $75 \%$ of votes with scores from $7-9$, it was dropped from the final item set. Output included two defined sets of attributes considered to be markers of severe disease, one for CD and one for UC (Supplemental Tables 1 and 2).

\section{PHASE 2: Conjoint analysis}

\section{Conjoint Analysis in Healthcare}

Conjoint Analysis (CA) has been used as a method to elicit how people make complex decisions with many driving factors by determining the willingness to "trade-off" certain attributes in favor of others. The CA process is a choice-experiment wherein we assume stakeholder choices are influenced by multiple driving forces that may be underlying. CA uses multinomial logit regression to model the choice process through applying multiple approximations of the utility of an attribute.

A particular form of CA, called Adaptive Choice-Based Conjoint (ACBC), takes respondents through a process of evaluating competing profiles of a product (or patient) that are comprised of various attributes, or characteristics. Increasingly, CA is being 
applied to healthcare decision-making processes. Examples of their applications include: conducting cost-effectiveness analysis with a consideration for process of care, assessment of willingness to pay, assessing health status, quality-adjusted life-years (QALY), health-related quality of life (HRQoL), and valuing patient-reported outcome measures to assess perceived risk and preference for various treatment options.[13-17] When making healthcare decisions, the profiles contain a list of patient clinical factors that influence a decision-making process, (e.g. frequency of loose stools, disease extent, and CRP level), each with a set of levels. This technique has been used previously to study patient and providers preferences in IBD.[18-21]

During a CA exercise, each response provided influences subsequent questions until there is ample consistency among respondent clinical factor choices to inform a series of complete hypothetical patient profiles containing varying levels of clinical attributes. In this project, participants were asked to focus on how different clinical factors of IBD influenced their impression of overall disease severity. Respondents indicate which patient profiles meet their evaluation criteria until finally, respondents are shown two side-by-side profiles and asked to select which is more severe. A series of profile comparison continues until the responses achieve internal consistency and a rank order of the respondent's prioritization of clinical factors can be determined.

\section{Survey Design}

The CA survey was created using the Sawtooth Software (Orem, UT) ACBC module. To conduct a CA exercise, it is essential that attributes are evaluated individually and partitioned into levels with varying degrees of severity. In March 2015, attributes and their corresponding levels were adapted for CA from the Frankfurt-based RAND panel (Table 1). 
The first section of the CA displayed a series of patient vignettes and respondents were asked to select either "Yes, this patient has severe disease" or "No, this patient does not have severe disease" (Figure 1). Each question in the CA was generated according to the respondent's previous selection. The length of the survey varied depending on the internal consistency of the responses. The next set of questions asked respondents to select from a list of attributes whether they believed any specific attributes to always be markers of severe disease, or were never markers of severe disease. Based off of respondents' selections, a series of side-by-side patients profiles was generated. Respondents then selected, amongst the two patients, which they believed had more severe disease. Some of the attributes remained constant between the two patient profiles. Respondents continued to select between pairs of patients until they established internal consistency and their preferences for certain attributes emerged. Figure 2 displays an example of the side-by-side comparison of two hypothetical Crohn's disease patients.

\section{Conjoint Analysis Administration}

In the context of this study, the CA methodology was applied to an in-person panel of experts to replace a traditional RAND decision panel. The underlying statistics behind CA are similar to that of regression modeling with the main output being a part-worth utility, or a number ranging from zero to one, with one being the most preferred and zero the least preferred clinical factor. The average importance of all clinical factors in the CA profiles add up to 1.0 (100 percent). It is through these outputs that we are able to see not only a rank ordering of attributes, but also the relative importance of one attribute compared to another, as well as the levels within each attribute. 
During the month of April 2015, we asked a selection of IBD specialists to complete the CA exercise at three different time points to determine the importance of each of the attributes as identified through the systematic review and then to determine if discussion of the attributes had an effect on their importance rankings. Initially, specialists completed the survey independently without any discussion or influence from others. All CA results were presented and reviewed anonymously at an in-person panel in Montreal, QC at the International Organization for the Study of Inflammatory Bowel Disease (IOIBD) Conference on April 23, 2015. After a period of discussion, experts then repeated the CA exercise in a group setting using an automated response system, (where the majority for question selection was set at 51\%). Finally, specialists completed the CA for a third time, independently, after commencement of the group discussion. This last round of ratings was used as the final results.

\section{PHASE 3: Disease Severity Score}

Following the compilation of third round of CA results, we worked to translate average importances into a baseline set of IBD severity scores that could be applied to the patient setting and in the future be adapted for use by clinicians in practice. To create the score, we utilized the average utility scores to determine minimum and maximum relative scores of each attribute level. Scores were converted to a 100-point scale, where the scores for the absence of a symptom within each attribute (the lowest average utility) were set to zero. Scores for levels within each attribute were calculated by applying the magnitude of their average utility to the attribute's overall importance, or weight. By applying the average utilities to the scoring schema, the score within a given attribute became relative to the level of importance that attribute had in determining severity across all of the clinical factors included in the CA. Scores within each attribute were rounded to the nearest integer. 


\section{Results}

\section{Sample Characteristics}

Eighteen IBD specialists completed the final CA exercise. Their ages were equally distributed from 35-65+, but only one was female. All participants had practiced medicine with a major interest in IBD for more than 10 years and were geographically diverse, representing 12 different countries.

\section{PHASE 1: Attribute Selection Process}

Following the initial panel (Supplemental Tables 1 and 2), specialists defined CD and UC severity using a set of 13 and 12 key attributes, respectively. To meet the parameters of CA methodology, some of these attributes were disassociated with one another; a process that would ensure each attribute would not be influenced by the presence of another. The final CA was comprised of 16 attributes for the CD module and 13 attributes for UC module (Table 1).

\section{PHASE 2: Pre-Meeting Versus Post-Meeting Conjoint Analysis Results}

There was a marked shift from the level of importance recorded from before and after the in-person discussion. Not only did the ranking of attribute importances shift within each disease state, but also, the rank orders differed between CD and UC. The presence of mucosal lesions was significantly more important than all other attributes under consideration in both modules. Figures $\mathbf{3}$ and $\mathbf{4}$ highlight the relative importance of each of the attributes for the $C D$ and $U C$ conjoint analysis modules from most to least influential when determining patient disease severity according to the post-meeting results. 


\section{Crohn's Disease Module}

Disease severity in $C D$ was dominated by those attributes measuring intestinal damage caused by disease, with mucosal lesions being the most influential clinical factor accounting for $18.1 \%$ of the determination of CD severity. Presence of a fistula (11\%), perianal abscess (9.7\%), and history of intestinal resection (7.4\%) were the next most prominent factors influencing the classification of severe disease (Table 2). Comparatively, the presence of daily symptoms (loose stools, experience with biologics, impacts daily activity), were less important factors influencing disease severity.

There was a significant increase in importance for clinical factors associated with intestinal damage following the in-person meeting in Montreal, suggesting that the distinction between CD and UC was influenced by the meeting's group discussions.

\section{Ulcerative Colitis Module}

In contrast to $C D, U C$ severity was influenced by the presence of inflammation and the impact of disease on daily activity. While the most important clinical factor for determining UC severity was mucosal lesions (18.1\%), the next was the impact of symptoms on daily activity (14.0\%). Use and effectiveness of biologics (10.1\%) and recent hospitalization (7.7\%) were also influential when determining disease severity. The clinical factors measuring intestinal damage were ranked much lower (disease extent, 4.8\%, anorectal symptoms, 4.0\%) (Table 2).

Comparing results from before and after the in-person meeting, those attributes exhibiting significant shifts in importance ranking included: impacts of daily activity, CRP level, experience with biologics, recent hospitalization, and recent steroid use. 


\section{PHASE 3: Overall disease severity index}

After examining the clinical attribute results for Crohn's disease and UC separately, we adapted the relative importance of each attribute to two unique 100-point scales. The severity scores calculated within attributes for Crohn's disease ranged from 16 (large or deep mucosal lesions as confirmed by MRI or endoscopy) to 2 (confirmed steroid use in the past year).

Disease severity scores calculated for the clinical attributes of UC ranged from 18 (active ulcers confirmed by endoscopy) down to 4 (presence of rectal bleeding, anorectal symptoms, or nocturnal bowel movements) (Tables $\mathbf{3 a}, \mathbf{3 b}$ ).

\section{Discussion}

Disease severity has historically been synonymous with disease activity, but this ignores the many different aspects of IBD that impact patients' lives and factors that lead to longterm complications. Disease activity can reflect long term or short term activity but is most often measured by a score that reflects only short term activity. These measures do not account for the accumulation of hospitalizations, surgeries, complications, associated diseases and impact on lifestyle over time. Intestinal damage begins soon after diagnosis, often in the absence of significant symptoms.[22] Although more prominent in $\mathrm{CD}$, this phenomenon also occurs in UC.[5] If effective therapy is reserved until moderate-severely active disease is obvious, then the window of opportunity to successfully treat patients to achieve remission is lost for many. To look beyond symptoms and better recognize patients at most risk due to their IBD, we have identified the key attributes that contribute to overall IBD severity. Furthermore, we have created two Overall Disease Severity Indices that can be tested to risk stratify patients with Crohn's disease and ulcerative colitis. 
Based on specialist opinion, mucosal lesions are the most important attribute associated with disease severity for both diseases. When comparing $C D$ and $U C, C D$ severity is associated more with accumulating intestinal damage, in contrast to UC disease severity, which is more dependent on symptoms and impact on daily life. This is consistent with how patients are approached in practice. For example, when patients with CD are seen in clinic, although current symptoms are taken into account, prior surgeries, perianal disease and extent of bowel at risk are typically weighted higher than day-to-day symptoms when considering a long-term treatment plan. Conversely, since active inflammation is more overt symptomatically with UC and bowel damage less obvious, it is not surprising that this expert panel treated UC differently than CD.

The work of this panel helps redefine overall disease severity for IBD. Currently, disease-scoring indices are used for clinical trials or to track symptoms prospectively.[23] These indices are valuable to stratify patients into mild, moderate or severe disease activity at a moment in time,[24] but do not take into account overall disease severity in context of bowel damage and impact on daily life. Other groups have identified risk factors for rapid evolution of disease,[25] disabling $C D,[26]$ and have defined features of severe, aggressive, or complicated $C D,[27-29]$ but have not specified and weighted how disease attributes independently contribute to overall disease severity. The disease characteristics identified by the panel, and the overall disease severity score will enable the differentiation between disease activity and disease severity and offer both further research opportunities and a practical tool by which to classify disease severity of patients and offer appropriate treatment without relying on present symptoms alone. In the early 1990s rheumatologists went through a similar process to identify better outcomes to measure for patients with rheumatoid arthritis and 
created OMERACT (Outcome Measures in Rheumatoid Arthritis Clinical Trials).[30] Since, this has become a foundation of their field and has led to hundreds of publications. We hope to learn from OMERACT, and use this current work to push the field of IBD towards a more meaningful understanding of overall disease severity.

As with any expert panel, there are limitations of this work based on the participants and validity outside of this group. Although the group was composed primarily of members from the IOIBD, this is a globally diverse cohort of specialists possessing varied opinions across a range of years of clinical experience. There was quite a bit of disagreement among the group in the pre-meeting independent questionnaires, but this gap decreased in the post-meeting voting - demonstrating that the RAND process is a successful method whereby people share opinions, listen to the views of others, and incorporate new points of view into an evolved perspective.

Conjoint analysis has been applied in healthcare fields ranging from mental health[31] to chronic leukemia,[32] and has been used specifically within the field of IBD.[19-21] The methodology of using conjoint tradeoff analysis embedded within a RAND panel is to the best of our knowledge, a novel approach. Integration of these two methodologies brings along with it the benefit of applying expert knowledge to a systematic process for assigning utilities scores to patient disease severity attributes, and then calculating specific values to explain what proportion of overall disease severity is influenced by each attribute.[33] This process could not be completed using a standard RAND format.

Future studies using these results should focus on two important aspects: prospective validation of the disease severity score in different patient populations, and conducting a similar in-person conjoint analysis with patients to see how their valuation of attributes 
compares to providers. After testing the application clinically, and refining based on patient input, it is likely that this overall IBD disease severity score could be adjusted and later implemented during clinical practice.

For patients with IBD, it is important to distinguish disease activity at a point in time from disease severity over a period of time. When selecting therapy for patients, providers need to focus on the short-term goal of controlling disease activity and use the overall disease severity to guide long-term management plans. Short-term symptom control is often the easiest part of IBD management, while preventing the consequences of irreversible bowel damage requires preparation and an understanding of the stratification of risk for an individual patient. We expect this work to help identify those at the higher end of the risk spectrum, so that appropriate intensive treatment can be initiated and optimized in an efficient, precise and cost-effective manner.

Acknowledgments: Phase 1 was funded thanks to an educational grant to IOIBD from Abbvie and Tillotts. We also thank Lucid for their logistical support during phases 1 and 2.

\section{References}

1. Gower-Rousseau, C., et al., Validation of the Inflammatory Bowel Disease Disability Index in a population-based cohort. Gut, 2015.

2. Peyrin-Biroulet, L., et al., Development of the first disability index for inflammatory bowel disease based on the international classification of functioning, disability and health. Gut, 2012. 61(2): p. 241-7.

3. Peyrin-Biroulet, L., et al., The natural history of adult Crohn's disease in population-based cohorts. Am J Gastroenterol, 2010. 105(2): p. 289-97.

4. Torres, J., et al., Ulcerative colitis as a sole mucosal disease: another misunderstanding? Gut, 2012. 61(4): p. 633.

5. Torres, J., et al., Ulcerative colitis as a progressive disease: the forgotten evidence. Inflamm Bowel Dis, 2012. 18(7): p. 1356-63. 
6. Khanna, R., et al., Early combined immunosuppression for the management of Crohn's disease (REACT): a cluster randomised controlled trial. Lancet, 2015. 386(10006): p. 1825-34.

7. Allen, P.B. and L. Peyrin-Biroulet, Moving towards disease modification in inflammatory bowel disease therapy. Curr Opin Gastroenterol, 2013. 29(4): p. 397-404.

8. Fiorino, G., et al., Preventing Collateral Damage in Crohn's Disease: The Lemann Index. J Crohns Colitis, 2016.

9. Pariente, B., et al., Development of the Lemann index to assess digestive tract damage in patients with Crohn's disease. Gastroenterology, 2015. 148(1): p. 52-63 e3.

10. Peyrin-Biroulet, L., et al., Defining Disease Severity in Inflammatory Bowel Diseases: Current and Future Directions. Clin Gastroenterol Hepatol, 2016. 14(3): p. 348-354 e17.

11. Best, W.R., et al., Development of a Crohn's disease activity index. National Cooperative Crohn's Disease Study. Gastroenterology, 1976. 70(3): p. 439-44.

12. Schroeder, K.W., W.J. Tremaine, and D.M. Ilstrup, Coated oral 5-aminosalicylic acid therapy for mildly to moderately active ulcerative colitis. A randomized study. N Engl J Med, 1987. 317(26): p. 1625-9.

13. Bridges, J.F., et al., Things are Looking up Since We Started Listening to Patients: Trends in the Application of Conjoint Analysis in Health 1982-2007. Patient, 2008. 1(4): p. 273-82.

14. Ryan, M. and K. Gerard, Using discrete choice experiments to value health care programmes: current practice and future research reflections. Appl Health Econ Health Policy, 2003. 2(1): p. 55-64.

15. Szeinbach, S.L., et al., Variables affecting pharmacists' willingness to accept third-party prescription contracts: a conjoint analysis. J Health Care Mark, 1990. 10(3): p. 45-50.

16. O'Brien, B.J., et al., Assessing the value of a new pharmaceutical. A feasibility study of contingent valuation in managed care. Med Care, 1998. 36(3): p. 37084.

17. McIntosh, E., Using discrete choice experiments within a cost-benefit analysis framework: some considerations. Pharmacoeconomics, 2006. 24(9): p. 85568.

18. Johnson, F.R., et al., Are gastroenterologists less tolerant of treatment risks than patients? Benefit-risk preferences in Crohn's disease management. J Manag Care Pharm, 2010. 16(8): p. 616-28.

19. Bewtra, M., et al., Patient preferences for surgical versus medical therapy for ulcerative colitis. Inflamm Bowel Dis, 2014. 20(1): p. 103-14.

20. Johnson, F.R., et al., Are adult patients more tolerant of treatment risks than parents of juvenile patients? Risk Anal, 2009. 29(1): p. 121-36.

21. Johnson, F.R., et al., Crohn's disease patients' risk-benefit preferences: serious adverse event risks versus treatment efficacy. Gastroenterology, 2007. 133(3): p. 769-79.

22. Cosnes, J., et al., Long-term evolution of disease behavior of Crohn's disease. Inflamm Bowel Dis, 2002. 8(4): p. 244-50. 
23. Sostegni, R., et al., Review article: Crohn's disease: monitoring disease activity. Aliment Pharmacol Ther, 2003. 17 Suppl 2: p. 11-7.

24. Lichtenstein, G.R., et al., Management of Crohn's disease in adults. Am J Gastroenterol, 2009. 104(2): p. 465-83; quiz 464, 484.

25. Van Assche, G., et al., The second European evidence-based Consensus on the diagnosis and management of Crohn's disease: Definitions and diagnosis. J Crohns Colitis, 2010. 4(1): p. 7-27.

26. Beaugerie, L., et al., Predictors of Crohn's disease. Gastroenterology, 2006. 130(3): p. 650-6.

27. Loly, C., J. Belaiche, and E. Louis, Predictors of severe Crohn's disease. Scand J Gastroenterol, 2008. 43(8): p. 948-54.

28. Yarur, A.J., et al., Predictors of aggressive inflammatory bowel disease. Gastroenterol Hepatol (N Y), 2011. 7(10): p. 652-9.

29. Zallot, C. and L. Peyrin-Biroulet, Clinical risk factors for complicated disease: how reliable are they? Dig Dis, 2012. 30 Suppl 3: p. 67-72.

30. Fried, B.J., M. Boers, and P.R. Baker, A method for achieving consensus on rheumatoid arthritis outcome measures: the OMERACT conference process. J Rheumatol, 1993. 20(3): p. 548-51.

31. Okumura, Y., et al., Expert opinions on the first-line pharmacological treatment for delirium in Japan: a conjoint analysis. Int Psychogeriatr, 2016: p. 1-10.

32. Landfeldt, E., et al., Patient, physician, and general population preferences for treatment characteristics in relapsed or refractory chronic lymphocytic leukemia: A conjoint analysis. Leuk Res, 2016. 40: p. 17-23.

33. Makkar, S.R., et al., Using conjoint analysis to develop a system to score research engagement actions by health decision makers. Health Res Policy Syst, 2015. 13: p. 22. 
Table 1. Clinical Factors (and levels) tested in conjoint analysis exercises.

\begin{tabular}{|c|c|c|c|}
\hline $\begin{array}{l}\text { Clinical Factor } \\
\text { (Crohn's } \\
\text { Disease) }\end{array}$ & Levels (Crohn's Disease) & $\begin{array}{l}\text { Clinical Factor } \\
\text { (Ulcerative } \\
\text { Colitis) }\end{array}$ & Levels (Ulcerative Colitis) \\
\hline $\begin{array}{l}\text { Mucosal } \\
\text { lesions }\end{array}$ & $\begin{array}{l}\text { - No mucosal lesions } \\
\text { - Small mucosal lesions as } \\
\text { confirmed by MRI or endoscopy } \\
\text { - Large or deep mucosal lesions as } \\
\text { confirmed by MRI or endoscopy }\end{array}$ & $\begin{array}{l}\text { Mucosal } \\
\text { lesions }\end{array}$ & $\begin{array}{l}\text { - No active erosions or ulcers } \\
\text { - Active erosions confirmed by } \\
\text { endoscopy } \\
\text { - Active ulcers confirmed by } \\
\text { endoscopy }\end{array}$ \\
\hline $\begin{array}{l}\text { Presence of a } \\
\text { fistula }\end{array}$ & $\begin{array}{l}\text { - No fistula at time of clinic visit } \\
\text { - Has fistula at time of clinic visit }\end{array}$ & $\begin{array}{l}\text { Impacts daily } \\
\text { activity }\end{array}$ & $\begin{array}{l}\text { - Disease does not significantly } \\
\text { impact daily activities } \\
\text { - Disease significantly impacts } \\
\text { daily activities }\end{array}$ \\
\hline $\begin{array}{l}\text { Presence of a } \\
\text { perianal } \\
\text { abscess }\end{array}$ & $\begin{array}{l}\text { - No perianal abscess at time of } \\
\text { clinic visit } \\
\text { - Has perianal abscess at time of } \\
\text { clinic visit }\end{array}$ & CRP level & $\begin{array}{l}\text { - Normal CRP levels (1-3 mg/L) } \\
\text { - Slightly elevated CRP levels (3-5 } \\
\text { mg/L) } \\
\text { - Elevated CRP levels (above } 5 \\
\text { mg/L) }\end{array}$ \\
\hline $\begin{array}{l}\text { History of } \\
\text { intestinal } \\
\text { resection }\end{array}$ & $\begin{array}{l}\text { - No intestinal resections } \\
\text { - At least one intestinal resection } \\
\text { less than } 40 \mathrm{~cm} \\
\text { - At least one intestinal resection } \\
\text { greater than or equal to } 40 \mathrm{~cm}\end{array}$ & $\begin{array}{l}\text { Experience } \\
\text { with biologics }\end{array}$ & $\begin{array}{l}\text { - Has never used } \\
\text { biologics/immunomodulators } \\
\text { - Has experienced some symptom } \\
\text { improvement with use of } \\
\text { biologics/immunomodulators } \\
\text { - Has not experienced symptom } \\
\text { improvement with use of } \\
\text { biologics/immunomodulators }\end{array}$ \\
\hline $\begin{array}{l}\text { Presence of a } \\
\text { stoma }\end{array}$ & $\begin{array}{l}\text { - No stoma at time of clinic visit } \\
\text { - Has stoma at time of clinic visit }\end{array}$ & $\begin{array}{c}\text { Recent } \\
\text { hospitalizations }\end{array}$ & $\begin{array}{l}\text { No disease-related } \\
\text { hospitalization within last } 12 \\
\text { months } \\
\text { Has disease-related } \\
\text { hospitalization within last } 12 \\
\text { months }\end{array}$ \\
\hline $\begin{array}{l}\text { Extent of } \\
\text { Disease }\end{array}$ & $\begin{array}{l}\text { - Limited disease (less than } 40 \mathrm{~cm} \\
\text { ileal involvement, OR absence of } \\
\text { pancolitis) }\end{array}$ & $\begin{array}{l}\text { Recent steroid } \\
\text { use }\end{array}$ & $\begin{array}{l}\text { - No steroid use within the past } \\
\text { year } \\
\text { - Has steroid use within the past }\end{array}$ \\
\hline
\end{tabular}




\begin{tabular}{|c|c|c|c|}
\hline & $\begin{array}{l}\text { - Extensive disease (ileal } \\
\text { involvement of at least } 40 \mathrm{~cm} \text { OR } \\
\text { presence of pancolitis) }\end{array}$ & & year \\
\hline $\begin{array}{l}\text { Frequency of } \\
\text { Loose stools }\end{array}$ & $\begin{array}{l}\text { - Less than } 10 \text { loose stools per } \\
\text { week } \\
\text { - At least } 10 \text { loose stools per week }\end{array}$ & Anemic & $\begin{array}{l}\text { - Not anemic (according to WHO } \\
\text { criteria) } \\
\text { - Yes, anemic (according to WHO } \\
\text { criteria) }\end{array}$ \\
\hline $\begin{array}{l}\text { Presence of a } \\
\text { stricture }\end{array}$ & $\begin{array}{l}\text { - No stricture at time of visit } \\
\text { - Has stricture at time of visit }\end{array}$ & Loose stools & $\begin{array}{l}\text { - No change in frequency of loose } \\
\text { stools compared to baseline } \\
\text { - Increase in frequency of loose } \\
\text { stools by one per day compared } \\
\text { to baseline } \\
\text { - Increase in frequency of loose } \\
\text { stools of at least two per day } \\
\text { compared to baseline }\end{array}$ \\
\hline CRP level & $\begin{array}{l}\text { - Normal CRP levels ( } 1-3 \mathrm{mg} / \mathrm{L} \text { ) } \\
\text { - Slightly elevated CRP levels (3-5 } \\
\text { mg/L) } \\
\text { - Elevated CRP levels (above } 5 \\
\text { mg/L) }\end{array}$ & Albumin level & $\begin{array}{l}\text { - Normal albumin level (more than } \\
\text { 3.5-5.0 g/dL) } \\
\text { - Low albumin level (less than } 3.5 \\
\text { g/dL) }\end{array}$ \\
\hline $\begin{array}{l}\text { Experience } \\
\text { with biologics }\end{array}$ & $\begin{array}{l}\text { - Has never used } \\
\text { biologics/immunomodulators } \\
\text { - Has experienced some symptom } \\
\text { improvement with use of } \\
\text { biologics/immunomodulators } \\
\text { - Has not experienced symptom } \\
\text { improvement with use of } \\
\text { biologics/immunomodulators }\end{array}$ & Disease extent & $\begin{array}{l}\text { - Distal colitis (inflammation } \\
\text { potentially treatable using } \\
\text { enemas) } \\
\text { - Extensive colitis (inflammation } \\
\text { extending beyond the reach of } \\
\text { enemas) }\end{array}$ \\
\hline $\begin{array}{l}\text { Impacts daily } \\
\text { activity }\end{array}$ & $\begin{array}{l}\text { - Disease does not significantly } \\
\text { impact daily activities } \\
\text { - Disease significantly impacts daily } \\
\text { activities }\end{array}$ & $\begin{array}{l}\text { Nocturnal } \\
\text { bowel } \\
\text { movements }\end{array}$ & $\begin{array}{l}\text { - Does not have nocturnal bowel } \\
\text { movements } \\
\text { - Has nocturnal bowel movements }\end{array}$ \\
\hline Albumin level & $\begin{array}{l}\text { - Normal albumin level (more than } \\
3.5 \mathrm{~g} / \mathrm{dL} \text { ) } \\
\text { - Low albumin level (less than } 3.5 \\
\text { g/dL] }\end{array}$ & $\begin{array}{l}\text { Anorectal } \\
\text { symptoms }\end{array}$ & $\begin{array}{l}\text { - None of the following: anorectal } \\
\text { pain, bowel urgency, } \\
\text { incontinence, discharge, } \\
\text { tenesmus } \\
\text { - At least one of the following: } \\
\text { anorectal pain, bowel urgency, } \\
\text { incontinence, discharge, } \\
\text { tenesmus }\end{array}$ \\
\hline $\begin{array}{l}\text { Anorectal } \\
\text { symptoms }\end{array}$ & $\begin{array}{l}\text { - None of the following: anorectal } \\
\text { pain, bowel urgency, } \\
\text { incontinence, discharge, } \\
\text { tenesmus } \\
\text { - At least one of the following: } \\
\text { anorectal pain, bowel urgency, } \\
\text { incontinence, discharge, } \\
\text { tenesmus }\end{array}$ & Rectal bleeding & $\begin{array}{l}\text { - No rectal bleeding } \\
\text { - Has rectal bleeding }\end{array}$ \\
\hline Anemia & $\begin{array}{l}\text { - Not anemic (according to WHO } \\
\text { criteria) } \\
\text { - Yes, anemic (according to WHO }\end{array}$ & & \\
\hline
\end{tabular}




\begin{tabular}{|c|l|l|}
\hline & criteria) & \\
\hline $\begin{array}{c}\text { Abdominal } \\
\text { pain }\end{array}$ & $\begin{array}{l}\text { - Infrequent abdominal pain (less } \\
\text { than daily) }\end{array}$ & \\
\hline $\begin{array}{c}\text { Recent } \\
\text { steroid use }\end{array}$ & $\begin{array}{l}\text { - No steroid use within past year } \\
\text { - Has used steroids within past year }\end{array}$ & \\
\hline
\end{tabular}

Table 2. Disease attribute contributions to overall disease severity

\begin{tabular}{|l|c|l|c|}
\hline Attribute of Crohn's & Proportion & Attribute of UC & Proportion \\
\hline Fistula & $15.8 \%$ & Mucosal lesions & $18.1 \%$ \\
\hline Perianal abscess & $10.9 \%$ & Impact on daily activities & $14.0 \%$ \\
\hline Prior bowel resection & $9.7 \%$ & C-reactive protein & $11.2 \%$ \\
\hline Stoma & $7.4 \%$ & Prior biologic use & $10.1 \%$ \\
\hline Disease extent & $7.1 \%$ & Recent hospitalization & $7.7 \%$ \\
\hline Frequency of loose stools & $5.8 \%$ & Recent steroid use & $7.6 \%$ \\
\hline Stricture & $5.6 \%$ & Anemia & $5.1 \%$ \\
\hline C-reactive protein & $5.4 \%$ & Frequency of loose stools & $4.8 \%$ \\
\hline Prior biologic use & $5.3 \%$ & Albumin & $4.8 \%$ \\
\hline Impact on daily activities & $5.3 \%$ & Disease extent & $4.8 \%$ \\
\hline Albumin & $4.8 \%$ & Nocturnal bowel movements & $4.3 \%$ \\
\hline Anorectal symptoms & $4.2 \%$ & Anorectal symptoms & $4.0 \%$ \\
\hline Anemia & $3.9 \%$ & Rectal bleeding & $3.5 \%$ \\
\hline Abdominal pain & $3.6 \%$ & & \\
\hline Recent steroid use & $3.1 \%$ & & \\
\hline
\end{tabular}

Table 3a Ulcerative Colitis Overall Disease Severity Index

\begin{tabular}{|c|c|c|}
\hline Attribute & Level & Score \\
\hline \multirow{3}{*}{ Mucosal lesions } & No active erosions or ulcers & 0 \\
\hline & Active erosions confirmed by endoscopy & 14 \\
\hline & Active ulcers confirmed by endoscopy & 18 \\
\hline \multirow{2}{*}{ Daily activity impact } & Disease does not significantly impact daily activities & 0 \\
\hline & Disease significantly impacts daily activities & 14 \\
\hline \multirow{3}{*}{ CRP level } & Normal CRP levels (1-3 mg/L) & 0 \\
\hline & Slightly elevated CRP levels (3-5 mg/L) & 4 \\
\hline & Elevated CRP levels (above 5 mg/L) & 11 \\
\hline
\end{tabular}




\begin{tabular}{|c|c|c|}
\hline \multirow{3}{*}{ Biologics use } & Has never used biologics/immunomodulators & 0 \\
\hline & $\begin{array}{l}\text { Has experienced some symptom improvement with use of } \\
\text { biologics/immunomodulators }\end{array}$ & 4 \\
\hline & $\begin{array}{l}\text { Has not experienced symptom improvement with use of } \\
\text { biologics/immunomodulators }\end{array}$ & 10 \\
\hline \multirow{2}{*}{ Recent hospitalization } & No disease-related hospitalization within last 12 months & 0 \\
\hline & Has disease-related hospitalization within last 12 months & 8 \\
\hline \multirow{2}{*}{ Steroid use } & No steroid use within the past year & 0 \\
\hline & Has steroid use within the past year & 8 \\
\hline \multirow{2}{*}{ Anemia } & Not anemic (according to WHO criteria) & 0 \\
\hline & Yes, anemic (according to WHO criteria) & 5 \\
\hline \multirow{3}{*}{ Frequency of loose stools } & No change in frequency of loose stools compared to baseline & 0 \\
\hline & $\begin{array}{l}\text { Increase in frequency of loose stools by one per day } \\
\text { compared to baseline }\end{array}$ & 5 \\
\hline & $\begin{array}{l}\text { Increase in frequency of loose stools of at least two per day } \\
\text { compared to baseline }\end{array}$ & 4 \\
\hline \multirow{2}{*}{ Albumin level } & Normal albumin level (more than $3.5-5.0 \mathrm{~g} / \mathrm{dL}$ ) & 0 \\
\hline & Low albumin level (less than $3.5 \mathrm{~g} / \mathrm{dL}$ ) & 5 \\
\hline \multirow{2}{*}{ Disease extent } & $\begin{array}{l}\text { Distal colitis (inflammation potentially treatable using } \\
\text { enemas) }\end{array}$ & 0 \\
\hline & $\begin{array}{l}\text { Extensive colitis (inflammation extending beyond the reach of } \\
\text { enemas) }\end{array}$ & 5 \\
\hline \multirow{2}{*}{$\begin{array}{l}\text { Nocturnal bowel } \\
\text { movements }\end{array}$} & Does not have nocturnal bowel movements & 0 \\
\hline & Has nocturnal bowel movements & 4 \\
\hline \multirow{2}{*}{ Anorectal symptoms } & $\begin{array}{l}\text { None of the following: anorectal pain, bowel urgency, } \\
\text { incontinence, discharge, tenesmus }\end{array}$ & 0 \\
\hline & $\begin{array}{l}\text { At least one of the following: anorectal pain, bowel urgency, } \\
\text { incontinence, discharge, tenesmus }\end{array}$ & 4 \\
\hline \multirow{2}{*}{ Rectal Bleeding } & No rectal bleeding & 0 \\
\hline & Has rectal bleeding & 3 \\
\hline
\end{tabular}

\section{Table 3b. Crohn's Disease Overall Severity Index}

\begin{tabular}{|l|l|c|}
\hline Attribute & Level & Score \\
\hline Mucosal lesions & So mucosal lesions & 0 \\
\hline & $\begin{array}{l}\text { Small mucosal lesions as confirmed by MRI or endoscopy } \\
\text { Large or deep mucosal lesions as confirmed by MRI or } \\
\text { endoscopy }\end{array}$ & 16 \\
\hline
\end{tabular}




\begin{tabular}{|c|c|c|}
\hline \multirow{2}{*}{ Fistula } & No fistula at time of clinic visit & 0 \\
\hline & Has fistula at time of clinic visit & 11 \\
\hline \multirow{2}{*}{ Perianal abscess } & No perianal abscess at time of clinic visit & 0 \\
\hline & Has perianal abscess at time of clinic visit & 10 \\
\hline \multirow{3}{*}{ Intestinal resections } & No intestinal resections & 0 \\
\hline & At least one intestinal resection less than $40 \mathrm{~cm}$ & 2 \\
\hline & At least one intestinal resection greater than or equal to $40 \mathrm{~cm}$ & 7 \\
\hline \multirow{2}{*}{ Stoma } & No stoma at time of clinic visit & 0 \\
\hline & Has stoma at time of clinic visit & 7 \\
\hline \multirow{2}{*}{ Disease extent } & $\begin{array}{l}\text { Limited disease (less than } 40 \mathrm{~cm} \text { ileal involvement, OR absence } \\
\text { of pancolitis) }\end{array}$ & 0 \\
\hline & $\begin{array}{l}\text { Extensive disease (ileal involvement of at least } 40 \mathrm{~cm} \text { OR } \\
\text { presence of pancolitis) }\end{array}$ & 6 \\
\hline \multirow{2}{*}{ Frequency loose stools } & Less than 10 loose stools per week & 6 \\
\hline & At least 10 loose stools per week & 0 \\
\hline \multirow{2}{*}{ Stricture } & No stricture at time of visit & 0 \\
\hline & Has stricture at time of visit & 5 \\
\hline \multirow{3}{*}{ CRP level } & Normal CRP levels (1-3 mg/L) & 0 \\
\hline & Slightly elevated CRP levels (3-5 mg/L) & 2 \\
\hline & Elevated CRP levels (above 5 mg/L) & 5 \\
\hline \multirow{3}{*}{ Biologics use } & Has never used biologics/immunomodulators & 0 \\
\hline & $\begin{array}{l}\text { Has experienced some symptom improvement with use of } \\
\text { biologics/immunomodulators }\end{array}$ & 2 \\
\hline & $\begin{array}{l}\text { Has not experienced symptom improvement with use of } \\
\text { biologics/immunomodulators }\end{array}$ & 5 \\
\hline \multirow{2}{*}{ Daily activity impact } & Disease does not significantly impact daily activities & 0 \\
\hline & Disease significantly impacts daily activities & 5 \\
\hline \multirow{2}{*}{ Albumin level } & Normal albumin level (more than $3.5 \mathrm{~g} / \mathrm{dL}$ ) & 0 \\
\hline & Low albumin level (less than $3.5 \mathrm{~g} / \mathrm{dL}$ ) & 4 \\
\hline \multirow{2}{*}{ Anorectal symptoms } & $\begin{array}{l}\text { None of the following: anorectal pain, bowel urgency, } \\
\text { incontinence, discharge, tenesmus }\end{array}$ & 4 \\
\hline & $\begin{array}{l}\text { At least one of the following: anorectal pain, bowel urgency, } \\
\text { incontinence, discharge, tenesmus }\end{array}$ & 0 \\
\hline \multirow{2}{*}{ Anemia } & Not anemic (according to WHO criteria) & 0 \\
\hline & Yes, anemic (according to WHO criteria) & 4 \\
\hline \multirow{2}{*}{ Abdominal pain } & Infrequent abdominal pain (less than daily) & 0 \\
\hline & Daily abdominal pain & 3 \\
\hline \multirow{2}{*}{ Steroid use } & No steroid use within the past year & 0 \\
\hline & Has steroid use within the past year & 2 \\
\hline
\end{tabular}




\section{Supplemental Table 1. Crohn's Disease Statements Following Phase 1}

\section{ITEMS \\ CRITERIA}

\section{IMPACT OF DISEASE}

Clinical symptoms

Frequency of loose stool (>10/week) and/or daily abdominal pain (pain scale >1)

Anorectal symptoms (pain, urgency, incontinence, discharge, tenesmus, active fistula)

Impact on daily activities

Disease having significant impact on daily activities

INFLAMMATORY BURDEN

Serum biomarkers

Anaemia (WHO criteria; abnormal) and/or elevated CRP (cut off 5) and/or low albumin

Mucosal lesions (MRI, endoscopy)

Active; If yes: large and/or deep ulcers

\section{DISEASE COURSE}

Complicated disease

Fistula at time of clinic visit and/or abscess at time of clinic visit and/or stricture at time of clinic visit and/or stoma at time of clinic visit and/or $>1$ intestinal resection or 1 intestinal resection $>40 \mathrm{~cm}$

Steroid use within past year and/or failure of biologics and/or

Response to medication

Disease extent immunomodulators

Extensive disease (>40 cm ileal involvement and/or pancolitis)

\section{Supplemental Table 2. UC Statements Following Phase 2}

\section{ITEMS CRITERIA}

IMPACT OF DISEASE

Clinical symptoms

Frequency of loose stool (>1 above baseline) and/or rectal bleeding (present or absent) and/or nocturnal bowel movements 


\begin{tabular}{|l|l|}
\hline & $\begin{array}{l}\text { Anorectal symptoms (pain, urgency, incontinence, discharge, } \\
\text { tenesmus) }\end{array}$ \\
\hline Impact on daily activities & Disease having significant impact on daily activities \\
\hline INFLAMMATORY BURDEN & $\begin{array}{l}\text { Anemia (WHO criteria; abnormal) and/or elevated CRP (cut off 5) } \\
\text { and/or low albumin }\end{array}$ \\
\hline Serum biomarkers & Active; If yes: Erosions, ulcers and/or friability \\
\hline Mucosal lesions (endoscopy) & $\begin{array}{l}\text { Steroid use within past year and/or failure of biologics and/or } \\
\text { immunomodulators }\end{array}$ \\
\hline DISEASE COURSE & Extensive colitis \\
\hline Response to medication & Need for hospitalisation within last 12 months \\
\hline Disease extent & Need for hospitalisation
\end{tabular}

\section{Figure Legend}

\section{Figure 1. Sample patient vignette.}

Figure 2. Side-by side profiles of two hypothetical Crohn's disease patients generated by the conjoint analysis exercise.

Figure 3. Pre-Meeting and Post-Meeting Average Crohn's Disease Attribute Importances. Patient characteristics of CD ordered by relative importance based on conjoint analysis part-worth utilities before and after the in-person meeting in Montreal, Quebec. Bars are displayed with standard errors to highlight significant differences in the rankings between the two time periods. Mucosal lesions accounted for $17.6 \%$ and $15.8 \%$ of IBD severity followed by presence of a fistula $(5.7 \%$ and $10.9 \%)$ in pre and post-meeting results, respectively. Having a fistula, perianal abscess, or stoma, all became more important in determining disease severity after the meeting, while having a stricture, use of biologics, impacts on daily activity, albumin level, and being anemic, all became less important.

Figure 4. Pre-Meeting and Post-Meeting Average Ulcerative Colitis Importances. Patient characteristics of UC, ordered by relative importance based on conjoint analysis part-worth utilities before and after the in-person meeting in Montreal, Quebec. Bars are displayed with standard errors to highlight significant differences in the rankings between the two time periods. Mucosal lesions accounted for $18.4 \%$ and $18.1 \%$ of IBD severity followed by impacts on daily activity (9.3\% and $14.0 \%)$ in pre and post-meeting results, respectively. The relative rankings of impacts on daily activity, CRP level, experience with biologics and recent steroid use all increased after the in-person meeting. 


\section{Figure 1}

\section{Patient Vignette}

Take a look at this patient with Crohn's disease and tell us whether you think the patient's disease

is "severe" or not.

\begin{tabular}{|c|c|}
\hline Abdominal pain? & Daily abdominal pain \\
\hline Anorectal symptoms? & None of the following: anorectal pain, bowel urgency, incontinence, discharge, tenesmus \\
\hline Loose stools? & Less than 10 loose stools per week \\
\hline Impacts daily activity? & Disease does not significantly impact daily activities \\
\hline Mucosal lesions? & No mucosal lesions \\
\hline Anemic? & Yes, anemic (according to WHO criteria) \\
\hline CRP level & Elevated CRP levels (above $5 \mathrm{mg} / \mathrm{L}$ ) \\
\hline Albumin level & Low albumin level (less than $3.5 \mathrm{~g} / \mathrm{dL}$ ) \\
\hline Has a fistula? & Has fistula at time of clinic visit \\
\hline Has a perianal abscess? & No perianal abscess at time of clinic visit \\
\hline Has a stricture? & Has stricture at time of visit \\
\hline Has a stoma? & No stoma at time of clinic visit \\
\hline $\begin{array}{l}\text { History of intestinal } \\
\text { resection? }\end{array}$ & No intestinal resections \\
\hline Recent steroid use? & No steroid use within the past year \\
\hline $\begin{array}{l}\text { Experience with } \\
\text { biologics? }\end{array}$ & Has never used biologics/immunomodulators \\
\hline Disease extent & Extensive disease (ileal involvement of at least $40 \mathrm{~cm}$ OR presence of pancolitis) \\
\hline
\end{tabular}




\section{Figure 2}

\section{Side-by-Side Comparison}

This next section will present pairs of patients. For each pair, select which of the two you think has more severe disease.

We've grayed out any clinical factors that are the same, so you can just focus on the differences.

We understand that the differences might be minimal between the two patients, but please do your best to select one patient.

\begin{tabular}{|c|c|c|}
\hline Abdominal pain? & Infrequent abdominal pain (less than daily) & Daily abdominal pain \\
\hline Anorectal symptoms? & $\begin{array}{l}\text { None of the following: anorectal pain, bowel urgency, } \\
\text { incontinence, discharge, tenesmus }\end{array}$ & $\begin{array}{l}\text { None of the following: anorectal pain, bowel urgency, } \\
\text { incontinence, discharge, tenesmus }\end{array}$ \\
\hline Loose stools? & At least 10 loose stools per week & Less than 10 loose stools per week \\
\hline Impacts daily activity? & Disease significantly impacts daily activities & Disease significantly impacts daily activities \\
\hline Mucosal lesions? & $\begin{array}{l}\text { Large or deep mucosal lesions as confirmed by MRI } \\
\text { or endoscopy }\end{array}$ & $\begin{array}{l}\text { Small mucosal lesions as confirmed by MRI or } \\
\text { endoscopy }\end{array}$ \\
\hline Anemic? & Not anemic (according to WHO criteria) & Not anemic (according to WHO criteria) \\
\hline CRP level & Slightly elevated CRP levels (3-5 mg/L) & Slightly elevated CRP levels (3-5 mg/L) \\
\hline Albumin level & Normal albumin level (more than $3.5 \mathrm{~g} / \mathrm{dL}$ ) & Low albumin level (less than $3.5 \mathrm{~g} / \mathrm{dL}$ ) \\
\hline Has a fistula? & No fistula at time of clinic visit & No fistula at time of clinic visit \\
\hline $\begin{array}{l}\text { Has a perianal } \\
\text { abscess? }\end{array}$ & No perianal abscess at time of clinic visit & Has perianal abscess at time of clinic visit \\
\hline Has a stricture? & Has stricture at time of visit & Has stricture at time of visit \\
\hline Has a stoma? & No stoma at time of clinic visit & Has stoma at time of clinic visit \\
\hline $\begin{array}{l}\text { History of intestinal } \\
\text { resection? }\end{array}$ & At least one intestinal resection less than $40 \mathrm{~cm}$ & $\begin{array}{l}\text { At least one intestinal resection greater than or equal } \\
\text { to } 40 \mathrm{~cm}\end{array}$ \\
\hline Recent steroid use? & Has steroid use within the past year & Has steroid use within the past year \\
\hline $\begin{array}{l}\text { Experience with } \\
\text { biologics? }\end{array}$ & $\begin{array}{l}\text { Has not experienced symptom improvement with use } \\
\text { of biologics/immunomodulators }\end{array}$ & Has never used biologics/immunomodulators \\
\hline Disease extent & $\begin{array}{l}\text { Extensive disease (ileal involvement of at least } 40 \mathrm{~cm} \\
\text { OR presence of pancolitis) }\end{array}$ & $\begin{array}{l}\text { Extensive disease (ileal involvement of at least } 40 \mathrm{~cm} \\
\text { OR presence of pancolitis) }\end{array}$ \\
\hline
\end{tabular}


Figure 3.

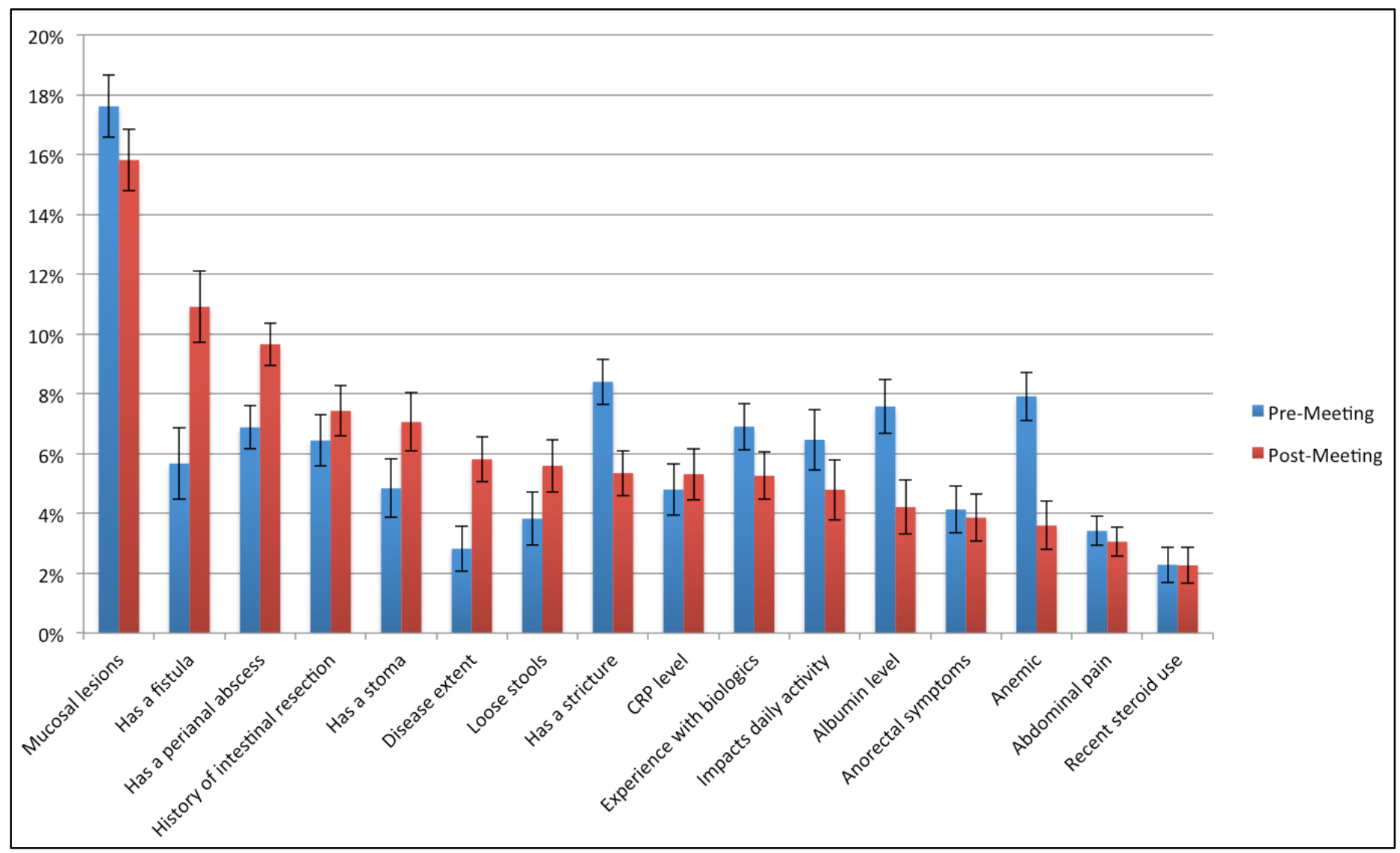


Figure 4

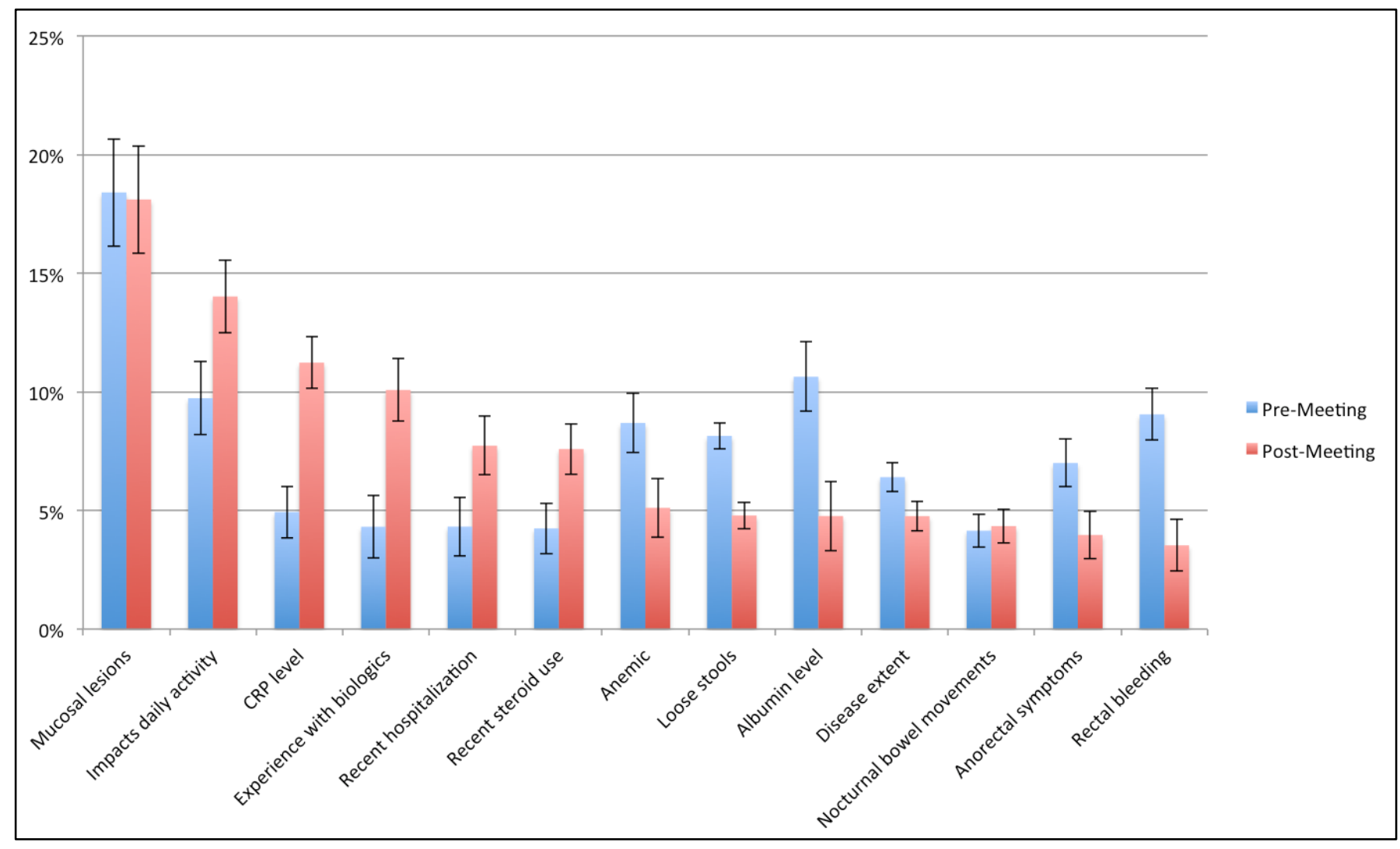

